\title{
Sand-enteropathy in 35 equids in Switzerland
}

\author{
Claudia Graubner', Maja Waschk², Hélène Aepli', Stephanie Stauffer ${ }^{7}$ and Vinzenz Gerber ${ }^{1}$ \\ 1 Institut Suisse de Médecine Equine ISME, Vetsuisse Fakultät, Universität Bern, Bern, Switzerland \\ ${ }^{2}$ Agroscope, Bern, Switzerland
}

\begin{abstract}
Summary: This retrospective case series describes sand-enteropathy in 35 cases presented at the Institut suisse de médecine équine (ISME) of the University of Bern since 2004 and up to July 2016. Horses and ponies were referred due to colic or abdominal discomfort. Impaction due to sand has increasingly been observed since 2004 and, compared to the general hospital population, Shetland-Ponies were overrepresented with $48 \%$. Besides clinical examination, abdominal radiographs were performed in 23 horses and quantity of sand was scored in a standardized fashion using three different scoring systems, which showed satisfactory to excellent agreement. Twentyfour horses (70\%) were treated medically and in 11 (30\%) a laparotomy was performed. Survival rate to discharge of the hospital was $91.4 \%(3 / 35)$ and was $85 \%(27 / 32)$ one year following discharge. Stronger disease awareness towards sand-enteropathy in equids is warranted. Abdominal radiography is a sensitive non-invasive method for diagnosing large colon sand impaction, especially in smaller breeds and for judging the amount of sand and should be used to control sand elimination over time. Although there is a risk of colitis and recurrent colic due to mucosal irritation generally, sand-enteropathy has a good prognosis at long-term in our hospital population.
\end{abstract}

Keywords: Sand-enteropathy, Switzerland, retrospective, impaction, colic,

Citation: Graubner C., Waschk M., Aepli H., Stauffer S., Gerber V. (2017) Sand-enteropathy in 35 equids in Switzerland. Pferdeheilkunde 33, 37-42; DOI 10.21836/PEM20170105

Correspondence: Dr. Claudia Graubner, Institut Suisse de Médecine Equine ISME, Vetsuisse Fakultät, Universität Bern und Agroscope, Länggassstrasse 124,3010 Bern, Switzerland; e-mail: claudia.graubner@vetsuisse.unibe.ch

\section{Introduction}

Sand-enteropathy is associated with signs of abdominal discomfort and distress such as colic, diarrhea, loss of appetite, lethargy and chronic weight loss in horses (Hart et al. 2013, Höppner et al. 2001, Lopes et al 2009, Ragle et al. 1989, Udenberg 1979). It is a known cause of intraluminal impaction and later mucosal abrasion and inflammation of the large colon (Bertone et al. 1988). In the past ten years, sand gastro-enteropathy has also become more frequent in Central Europe (Höppner et al.2001, Lopes et al. 2009, Maxwell et al. 2003), particularly in our clinical case load in Switzerland. This increase appears to coincide with the increasing popularity of certain housing systems, including time spent on pasture and on paddocks. It also may be associated with horse and pony breeds that entertain a particularly good and sometimes perhaps indiscriminate appetite. Between 2002 and 2014 , the proportion of housing systems that allow permanent outdoor access increased from 16.5 to $24 \%$ (Kiener et al. 2016). In Switzerland, pasture surfaces available per animal are often small and overgrazing occurs frequently. Allweather premises are mostly designed with sand or gravel surfaces and roughage is often fed on the ground. Together with the changes in housing systems, the number of "pet" equids of breeds displaying particularly well developed appetites, ranging from small ponies like mini-shetland ponies to middlesize horses like tinkers has increased (AGATE; Swiss internet portal for agriculture, animals and food; www.agate.ch).

Despite of these changes, awareness of sand gastro-enteropathy in Switzerland remains low, even amongst veterinary professionals. Diagnosis of sand enteropathy can be challenging and typically involves several of the following tests: general clinical examination including abdominal auscultation and rectal palpation, fecal sedimentation test, abdominal ultrasonography and radiography or exploratory laparotomy
(Höppner et al. 2001, Keppie et al. 2009, Korolainen et al. 2002, Ragle et al. 1989, Ruohoniemi et al. 2001). Medical and surgical treatment protocols for sand impaction have been described with good short-term survival, resulting in $85-90 \%$ of horses reported to be discharged from their hospitals after therapy of sand-gastroenteropathy (Granot et al. 2008, Hammock et al 1998, Hart et al. 2013, Höppner et al. 2001, Hotwanger et al. 2007, Maxwell et al. 2003). Long-term prognosis $\geq 1$ year is also documented to be good with $90 \%$ survival in uncomplicated cases provided that the housing management was adapted and improved (Hart et al. 2013).

The purpose of this retrospective study was to summarize epidemiological and clinical data of 35 patients with sandenteropathy that were presented to the Institut suisse de médecine équine (ISME) of the University of Berne and to compare radiological scores to evaluate the quantity of sand accumulation in the equine large colon.

\section{Materials and Methods}

Medical records between January 2004 and July 2016 of the Institut suisse de médecine équine (ISME) were searched using the terms "Sand", "Sandkolik" and "Sandenteropathie" (records are kept in German) for cases with sand-enteropathy. Case selection was based on clinical diagnosis which involved abdominal discomfort and colic as well as confirmation of sand involvement by fecal sedimentation, abdominal radiography, abdominal surgery or post mortem examination. Data were taken from the case history and a telephone questionnaire (see attachment in German). The minimal data base for each case included: sex, age, breed, husbandry and feeding management, use, presenting complaints, duration of 
complaints before presentation to the clinic, physical examination at the ISME on admission including heart and respiration rate, temperature and abdominal sounds on auscultation, gross abdominal distention requiring decompression through the right flank, reflux at admission, findings on rectal palpation, quality of feces and fecal sedimentation. Initial laboratory values were obtained and included hematology and biochemical values. Additional information on findings regarding abdominocentesis, abdominal ultrasonography and radiography were also recorded and analysed. Furthermore, data regarding medical treatment (intravenous fluids, oral laxatives, analgetic drugs) and surgical interventions were recorded, short- and long-term outcome, further diagnoses and complications were evaluated.

Radiographs were interpreted and scored by a second year resident in diagnostic imaging and findings were validated by a board certified radiologists. Four of 23 horses had followup radiographs performed after treatment. Radiographs were scored using the scoring system after Keppie et al. (2008). Results of this scoring system were compared to the systems of Hart et al. 2013 and Korolainen et al. 2002.

Using the statistical software NCSS 2010 Data were assessed descriptively. Furthermore, the three scoring systems were compared using Spearman-Rank correlations.

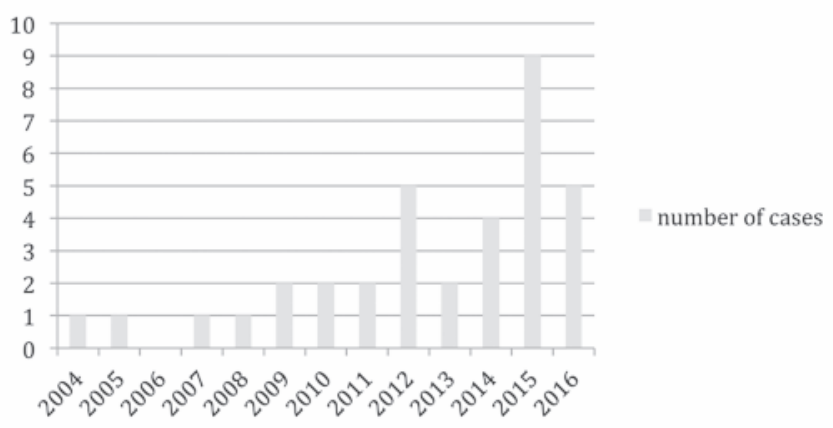

Fig 1 In the last 12 years the number of horses presented with large colon sand impaction increased.

\section{Results}

35 cases were diagnosed with sand enteropathy at the Institut suisse de médecine équine (ISME) of the University of Berne and fulfilled the inclusion criteria. Records were available of all horses. Case distribution between 2004 and 2016 is presented in Figure 1, illustrating cases per year. Figure 2 shows the case distribution over the seasons. Fourteen mares and 21 geldings with a mean age of 11.4 years (range from 2 month old to 28 years) were included. Shetland ponies were overrepresented with 20/35 (57\%). Other breeds were Camargue (1), Freiberger (1), Friesian (1), Haflinger (2), Irish Tinker (2), Pottock (1), Icelandic pony (1), Standardbred (1) and American Quarter Horse (1), Dutch Warmblood (1), unknown (2) as well one donkey.

\section{Clinical findings}

33 Horses were referred with signs of colic. Nine of these had a history of recurrent colic. One horse was presented due to chronic weight loss and abdominal discomfort and one due to loss of appetite and lethargy. One of the horses that presented with colic also had chronic weight loss and three had additional chronic diarrhea. Mean duration of clinical signs prior hospital admission was 22.6 hours with a range from 5 hours to 5 days.

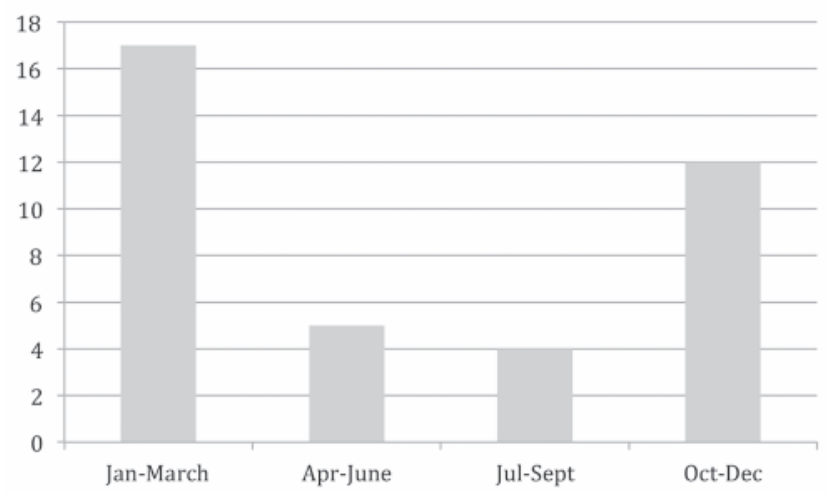

Fig 2 In autumn and winter significantly more cases of large colon sand impaction were observed.

Table 1 Laboratory findings

\begin{tabular}{|c|c|c|c|}
\hline & Mean & Standard deviation & Reference range \\
\hline Hematocrite I/I & 36.1 & 6.42 & $31-47$ \\
\hline Leucocyte count $\mathrm{G} / \mathrm{I}$ & 8.4 & 2.9 & 5.3-10.3 \\
\hline Band Neutrophils G/I & 0.28 & 0.4 & $0-0.5$ \\
\hline Segmented Neutrophils G/l & 5.9 & 2.9 & $2.5-6$ \\
\hline Lymphocytes G/I & 1.9 & 1.1 & $1.5-4$ \\
\hline Total protein $\mathrm{g} / \mathrm{l}$ & 71.1 & 8.96 & $54-73$ \\
\hline Lactate $\mathrm{mmol} / \mathrm{l}$ & 4.2 & 3.9 & $0-4$ \\
\hline Triglyceride mmol// & 1.3 & 1.9 & $0.1-0.39$ \\
\hline Creatinine mikromol// & 120 & 43 & $86-173$ \\
\hline Urea $\mathrm{mmol} / \mathrm{l}$ & 6.2 & 3.5 & $3.18-6.46$ \\
\hline Serum Amyloid A mikrog/ml & 464.75 & 1114.7 & $<8$ \\
\hline abdominocentesis Total protein $\mathrm{g} / \mathrm{l}$ & 22.5 & 8.12 & $<20$ \\
\hline abdominocentesis Lactate $\mathrm{mmol} / / \mathrm{l}$ & 8.3 & 7.9 & $0-2$ \\
\hline abdominocentesis Leucocytes G/l & 1 & 0.6 & $<5$ \\
\hline
\end{tabular}


Mean heart rate at admission was 60.4 beats/min (range from 36 to 116 beats/min), mean respiratory rate was 17.5 breaths/min (range from 12 to 40 breaths/min). Only one horse had a transiently elevated rectal temperature of $38.6^{\circ} \mathrm{C}$. Gut sounds were absent in two cases, reduced in 23 cases and normal in 8 cases. Thirteen horses showed gross abdominal distention, four of which had a transabdominal cecal puncture for decompression. One of these subsequently underwent surgical laparotomy. One horse had a gastric impaction and one horse had gastric reflux at admission. Body size and temperament permitted rectal examination in 17/35 cases, only digital palpation was possible in 5 ponies. In 9 of the 17 horses with a rectal examination, a large colon impaction was found. In one of those gravel was palpated in the large colon. Four of the 17 horses had a gas distended large colon, one had a left dorsal displacement of the large colon, one had a suspicion of a displacement to the right and another horse had no abnormal findings. Digital palpation revealed pure sand in the rectum of one of the ponys, otherwise no conclusions could be drawn. Sand accumulation in fecal sedimentation was observed on feces in 12/35 cases. The amount of sand was not quantified. The suspicion of sand-enteropathy was expressed after the clinical examination in 16/35 cases.

\section{Laboratory findings}

Results of hematology and blood chemistry are listed in table 1. The mean haematocrit was $36 \mathrm{l} / \mathrm{I}$ with a standard deviation of 7.08 and a range of 22-56 I/l. Mean total protein was $69.5 \mathrm{~g} / \mathrm{l}$ (SD 9.74; range from $52.1-89 \mathrm{~g} / \mathrm{l})$. Leucocytes ranged from 4.7-14.4G/l with a mean of $8.2 \mathrm{G} / \mathrm{l}$ (SD 3). Venous blood lactate was measured in $9 / 35$ cases with a mean $3.9 \mathrm{mmol} / \mathrm{l}$ (SD 3.3) and a range of $2.5-12 \mathrm{mmol} / \mathrm{l}$. Serum Amyloid A was elevated with a mean of $408.5 \mu \mathrm{g} / \mathrm{l}$ (SD 956.5). The remaining blood chemistry parameters were unremarkable.

\section{Diagnostic imaging}

Transabdominal ultrasound was performed in 22/35 cases. In no case it was diagnostic for large colon sand impaction. In ten cases an abdominocentesis was performed, with measured and increased lactate in four cases (lactate $>2 \mathrm{mmol} / \mathrm{l}$ ), increased total protein in 5 cases (TP $>20 \mathrm{~g} / \mathrm{l}$ ) and normal leucocytes in all cases (Lc $>5 \mathrm{G} / \mathrm{l}$ ). Intestinal parasitism was confirmed in 1 pony by positive fecal egg count on flotation and $1700 \mathrm{EpG}$ using the McMaster method. Radiographs were taken of 23/35 animals standing using a right laterolateral view of the cranioventral abdomen. The amount of sand was evaluated in a standardized fashion using three different scoring systems (Hart et al. 2013, Keppie et al. 2008, Korolainen et al. 2002) (Table 2). The three different scores were significantly correlated as assessed using SpearmanRank correlations. Correlation coefficients were $r=0.58$ $(p=0.0019)$ between the scores of Hart et al. and Keppie et al., $0.7(p<0.000)$ between the scores of Keppie et al. and Korolainen et al. and $0.89(p>0.000)$ between the scores of Hart et al. and Korolainen et al.. Four horses had follow-up radiographs performed between one and seven months after hospitalization. The progression of the radiological score is shown in figure $3 a-c$.

\section{Treatment}

Twentyfour horses were treated medically, 16 of which received intravenous fluid therapy, ten of which had a lidocain continuous rate infusion (CRI) over mean 3.2 days (SD $1.6 \mathrm{~d}$ ) $\left(0.05 \mathrm{mg} / \mathrm{kg} / \mathrm{min}\right.$, Lidocain $2 \%{ }^{\circledR}$, Chassot). Four of the medically treated horses received no analgetic drugs, five only had metamizol i.v. $\left(20 \mathrm{mg} / \mathrm{kg}\right.$ i.v., Vetalgin ${ }^{\circledR}$, MSD Animal Health Switzerland), two received only flunixin meglumin $(1.1 \mathrm{mg} / \mathrm{kg}$, Flunixine ${ }^{\circledR}$, Biokema) and twelve cases had a combination of both. The horses with a lidocaine CRI received metamizol and flunixin meglumin. Three of the medically treated horses had a transabdominal cecal decompression. Two of these horses received Penicillin $\left(20^{\prime} 000 \mathrm{lU} / \mathrm{kg} / \mathrm{q} 6\right.$ hours, Penicillin $\mathrm{Na}^{\circledR}$, Streuli) and Gentamicin $\left(6.6 \mathrm{mg} / \mathrm{kg}\right.$ q24 hours, Pargenta ${ }^{\circledR}$, Dr. E. Gräub AG) and one had Cefquinome (1 mg/kg q24 hours, Cobactan ${ }^{\circledR}$, MSD Animal Health Switzerland). Due to suspicion of colitis during the treatment, two other horses in the medically treated group received antibiotics (metronidazole $20 \mathrm{mg} / \mathrm{kg}$ every 8 hours p.o. and trimethoprim sulfonamide Rota $\mathrm{TS}^{\circledR}$, Vétoquinol $\mathrm{AG}$ ). Eleven horses were treated surgically with a ventral midline laparotomy. All received a postoperative intravenous therapy $(6$ substituted with lidocaine), antibiotics (10 cases penicillin, gentamicin, 1 cefquino-

\begin{tabular}{|c|c|c|c|}
\hline Table 2 & \multicolumn{3}{|c|}{ Radiographic scores of large colon sand impaction } \\
\hline Case number & Keppie score & $\begin{array}{c}\text { Hart score } \\
(\max 3)\end{array}$ & $\begin{array}{c}\text { Korolainen } \\
\text { score }(\max 4)\end{array}$ \\
\hline 10 & 6 & 1 & 2 \\
\hline 11 & 5 & 3 & 4 \\
\hline 12 & 10 & 1 & 2 \\
\hline 13 & 6 & 1 & 1 \\
\hline 14 & 8 & 3 & 4 \\
\hline 15 & 10 & 3 & 4 \\
\hline 16 & 11 & 1 & 3 \\
\hline 17 & 11 & 1 & 2 \\
\hline 19 & 12 & 2 & 3 \\
\hline 20 & 5 & 1 & 1 \\
\hline 21 & 10 & 2 & 4 \\
\hline 23 & 8 & 2 & 3 \\
\hline 24 & 5 & 1 & 1 \\
\hline 25 & 0 & 0 & 0 \\
\hline 26 & 9 & 2 & 4 \\
\hline 27 & 3 & 1 & 1 \\
\hline 28 & 11 & 2 & 2 \\
\hline 29 & 8 & 1 & 2 \\
\hline 30 & 4 & 1 & 1 \\
\hline 31 & 0 & 0 & 0 \\
\hline 32 & 1 & 1 & 1 \\
\hline 33 & 9 & 2 & 3 \\
\hline 34 & 8 & 2 & 2 \\
\hline 35 & 7 & 2 & 3 \\
\hline 36 & 0 & 0 & 0 \\
\hline 37 & 0 & 0 & 0 \\
\hline 42 & 7 & 2 & 3 \\
\hline
\end{tabular}


me) and flunixin meglumin. In all cases a colon impaction with sand was the intra-operative diagnosis. Enterotomy had to be performed to evacuate the sand from the large colon. One horse additionally had a large colon volvulus of $360^{\circ}$. All except one of the horses belonging to the surgical group received a laxative via the nasogastric tube. 31/35 cases received paraffin oil, 16/35 horses psyllium $(1 \mathrm{~g} / \mathrm{kg} / \mathrm{d})$ and $10 / 35$ additional Natriumsulfate (50-250g in water/horse). One pony was treated for a concurrent conjunctivitis and another for a thrombophlebitis.

In this case series, $85 \%$ of the horses were alive one and more years after hospitalization. Three of 35 were euthanized during hospitalization $(8.5 \%$, one had a peritonitis and paralytic ileus after laparotomy, one a gastric rupture and one did
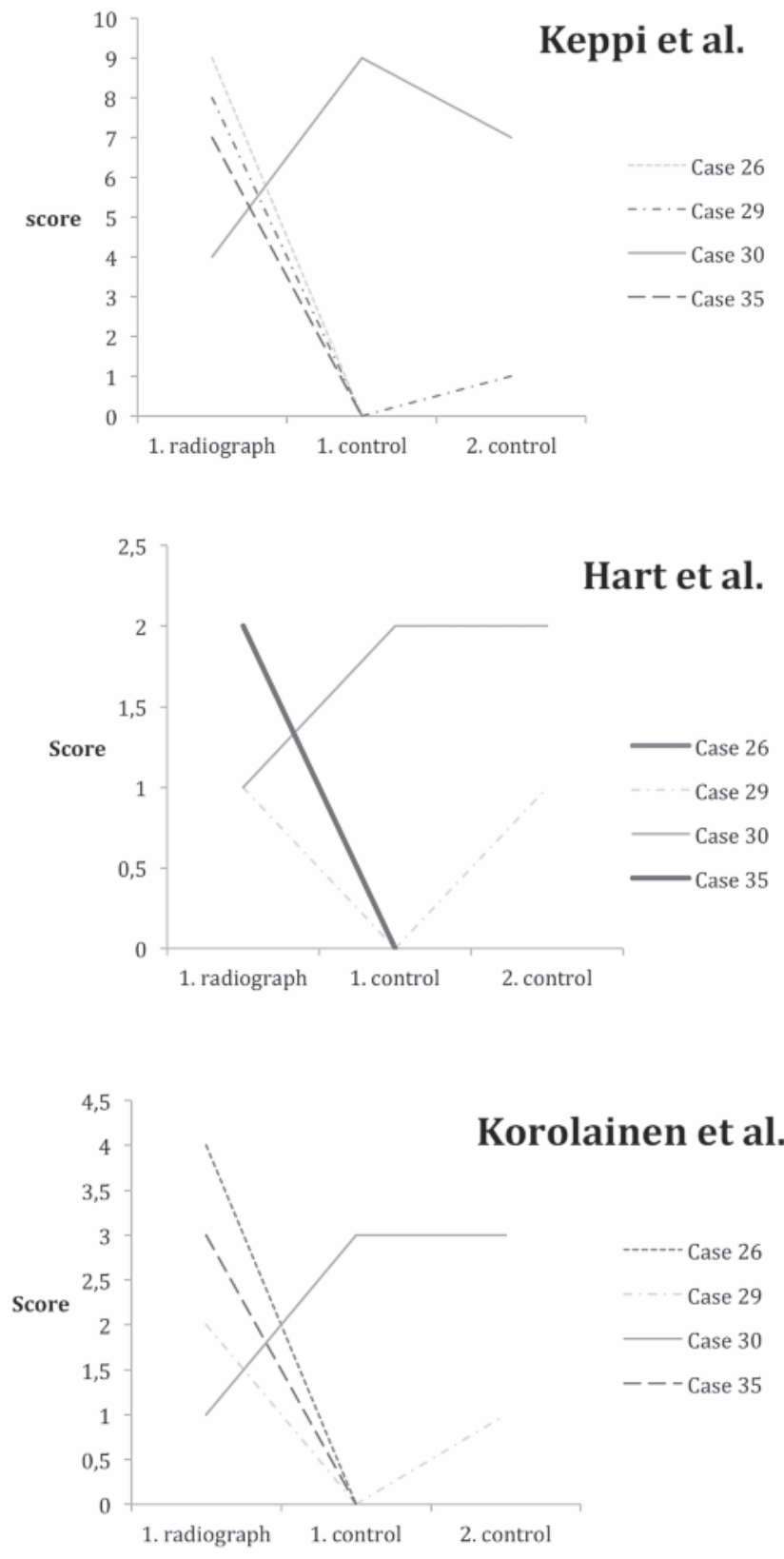

Fig. 3 a-c Radiographic scoring using the three different scoring systems of Keppi et al., Hart et al. and Korolainen et al. in 4 cases with repeated transabdominal radiographs. The figures show the progression of sand elimination between the first and second radiograph in case 26 and 35 and three radiographs in case 29 and 30. not respond to medical treatment and did not have permission for surgery. Of the remaining 32 cases, five were reported to be deceased. Four of them were humanely destroyed due to recurrent colic and colitis and one for reasons unrelated to gastrointestinal disease.

The most common complications after sand colic in this population were recurrent colic $(n=3)$ and colitis $(n=4)$. Time of hospitalization was mean $7.5 \mathrm{~d}$ (range 1-19d).

\section{Discussion}

In this case series, the increasing occurrence of large colon sand impaction in equids in Switzerland is reported. Regarding breeds, Shetland ponies were overrepresented with $48 \%$. This might be explained by an increase of Shetland ponies kept as "pets" and the concomitant increase in the popularity of extensive housing systems, where Ponies and other breeds with a tendency to display "overly healthy" appetites and perhaps indiscriminate eating habits are being kept. All horses were used as pleasure riding horses or as companion animals to other equids. At the School of Agricultural, Forest and Food sciences, the development of equine housing systems in Switzerland was examined and it was found out that extensive housing systems have become more popular in recent years (Kiener et al. 2016). Horses used for pleasure riding are frequently kept in groups and extensive housing systems with access to sand paddocks or pasture. In seasons were less grass was available (autumn, winter) significantly more cases were referred with large colon sand impaction. During the colder seasons, horses are less kept on pasture but more on all weather paddocks which could explain an increased ingestion of sand when horses were fed from the ground.

Ninetyfour percent (33/35) of the cases were presented due to acute colic. None of them showed clinical signs consistent with shock. In $45 \%$ the clinical suspicion of sand impaction was expressed at the referral clinic, more frequently in the second half of the time period of this retrospective case series. This suggests that alertness in the ISME equine clinic toward the colic etiology "sand impaction" has been increasing over the last years. Nevertheless, this specific cause of colic does not seem to be familiar to the majority of horse owners as most of the time they were surprised when learning of the diagnosis.

In twelve horses (34\%) the sand sedimentation test in a rectal sleeve was positive. This test should be undertaken when sand is suspected to be the reason for colic, although it has not been found to be highly specific (Ragle et al. 1989).

Transabdominal ultrasound was performed in 22 cases but sand impaction was never diagnosed. Thus, in our hands sonography does not really appear to be helpful, except to exclude other pathologies. Nevertheless, it may be interesting to note that large colon architectural changes like "flat" appearance or a thickened gut wall were recorded in 9 cases. As it is difficult to differentiate between air-ingesta interface or sand-air-ingesta interface at the ventral border of the large colon, it is plausible that the etiological diagnosis of an impacted colon is not straight forward ultrasonically. A thickened colon wall resulting from chronic irritation due to a sand 
impaction may be observed in some cases. It cannot be excluded that more large colon sand impactions would have been diagnosed if ultrasound had been performed by a specialist of diagnostic imaging. Latero-lateral abdominal radiographs were performed in 23 cases. Three different scores where used to objectively quantify the amount of sand and to judge if the amount of sand was likely to be responsible for the colic signs. The scores showed correlations among themselves that ranged from satisfactory to excellent. The score that only showed satisfactory correlation with the other two, the one by Keppi et al. however, was prefered by the evaluating radiologist, because it offered the largest range for scoring. Unfortunately, no pain score was used in this population, so comparison of clinical signs and radiological scoring was not possible.

Regarding treatment, one third of the cases underwent surgery. In only two of them sand impaction was a differential diagnosis pre-operatively. One horse died due to a colitis caused by Salmonella after surgery. Reportedly, colic surgery in horses with large colon sand impaction has a good prognosis (Granot et al. 2008), although, eliminating the sand by an enterotomy can lead to mucosal irritation and an increased risk for the development of colitis. Horses that undergo surgery due to a large colon sand impaction are at a risk of endotoxemia and therefore preventative medical measures should be considered particularly if further suggestive clinical or laboratory signs such as reddened mucous membranes or "toxic" changes in the leukogram, respectively, are observed. Colon sand impaction can also lead to diarrhea and colitis without the sand being eliminated surgically (Bertone et al. 1988).

Medical treatment for large colon sand impaction can be treated medically in most cases (Huskamp et al. 1999). Medically treated horses were likely often discharged from the ISME equine hospital before the sand could be eliminated completely. Studies showed that using a combination of magnesiumsulfate and psyllium or mineral oil and psyllium as a laxative can eliminate sand from the large colon within four days (Hotwanger et al. 2008, Niinistö et al. 2014, Ruohoniemi et al. 2001). Our follow-up control radiographs were performed at least four weeks after discharge from the clinic. Therefore, our results cannot be compared to the studies mentioned above and we cannot make conclusions about the efficacy of laxatives used during hospitalization.

Clear recommendations to owners to improve housing systems appear critical for long-term outcome. Free access to a sandy paddocks should be avoided. Most importantly, they should not be fed from the ground and if pasture consists more of dirt than grass, a muzzle should be used or access restricted until grass has regrown. Also, those horses should not be grazed when there are new grass shoots with loose roots. Daily exercise should be encouraged to stimulate gut motility and facilitate elimination of sand. High roughage diets have also been shown to reduce the likelihood of developing sand impactions in horses with exposure to sand (Hammock et al. 1998). Laxatives given via nasogastric tube can be considered as both a preventative and as a treatment option, depending on dose and frequency given, but require veterinary intervention.

In conclusion, sand impaction as the underlying cause for gastrointestinal signs should be considered particularly in horses of "breeds with overly healthy appetites" kept extensively. This case series indicates that this problem is occurring with increasing frequency. A good clinical history, thorough clinical examination including rectal examination, complemented by a sand sedimentation test can lead to the differential diagnosis of sand impaction. If the general condition of the horse permits and the presence of significant amounts of abdominal sand accumulations needs to be confirmed or refuted as a reason for colic, transabdominal latero-lateral radiographs should be performed to confirm the presence of sand within the large colon.

\section{Acknowledgements}

Thanks to the team of the Division of clinical radiology of the Department of Clinical Veterinary Medicine in the Vetsuisse Faculty of the University of Bern for reviewing radiographic scoring.

\section{References}

Bertone J. J., Traub-Dergatz J. L., Wrigley R. W., Bennet D. G., Williams R. J. (1988) Diarrhea associated with sand in the gastrointestinal tract of horses. J. Am. Vet. Med. Assoc. 193, 1409-1412

Granot N., Milgram J., Bdolah-Abram T., Shemesh I., Steinman A. (2008) Surgical management of sand colic impactions in horses: a retrospective study of 41 cases. Austr. Vet. J. 10, 404-407

Hammock P. D., Freeman M. V. B., Baker J. G. (1998) Failure of Psyllium Mucilloid to Hasten Evacuation of Sand From the Equine Large Intestine. Vet. Surg. 27, 547-554

Hart K. A., Linnenkohl W., Mayer J. R., House A. M., Gold J. R., Giguère S. (2013) Medical management of sand enteropathy in 62 horses. Equine Vet. J. 45, 465-469

Höppner S. (2001) Sandkolik beim Pferd - Diagnostik, konservative und chirurgische Behandlung. Pferdeheilkunde 17, 406-407

Hotwagner K., Iben C. (2008) Evacuation of sand from the equine intestine with mineral oil, with and without psyllium. J. Anim. Physiol. Anim. Nutr. 92, 86-91

Huskamp B., Dietz O. (1999) Handbuch Pferdepraxis, Kap. 24 Magen-Darm-Trakt, 473

Keppie N., Rosenstein D. S., Holcombe S. J., Schott H. C. (2008) Objective radiographic assessment of abdominal sand accumulation in horses. Ultrasound 49, 122-128

Kiener B.(2016) Bachelorarbeit HAFL Bern zur Umstellung auf Gruppenhaltung bei Pferden. unpublished

Korolainen R., Ruohoniemi M. (2002) Reliability of ultrasonography compared to radiography in revealing intestinal sand accumulations in horses. Equine Vet. J. 34, 499-504

Lopes M. A. F. (2009) Intraluminal Obstruction of The Large Colon. In Current Therapy in Equine Medicine 6. Robinson N.W., Sprayberry K. A., 410-411

Maxwell J. (2003) The surgical management of sand impaction in a Miniature Horse. Aust. Vet. J. 81, 547-548

Niinistö K., Hewetson M., Kaikkonen R., Sykes B. W., Raekallio M. (2014) Comparison of the effects of enteral psyllium, magnesium sulphate and their combination for removal of sand from the large colon of horses. Vet J. 202, 608-611

Ragle C. A., Meagher D. M., Schrader J. L., Honnas C. M. (1989) Abdominal auscultation in the detection of experimentally induced gastrointestinal sand accumulation. J. Vet. Int. Med. 3, 12-14

Ruohoniemi M., Kaikkonen R., Raekallio M., Luukkanen L. (2001) Abdominal radiography in monitoring the resolution of sand accumulations from the large colon of horses treated medically. Equine Vet. J. 33, 59-64

Udenberg T. (1979) Equine Colic Associated with Sand Impaction of the Large Colon. Can. Vet. J. 20, 269-272 